07

\title{
Температурный режим и механические напряжения в корпусированных фотоэлектрических преобразователях концентрированного солнечного излучения
}

\author{
(C) А.Н. Паньчак, М.3. Шварц \\ Физико-технический институт им.А.Ф.Иоффре РАН, \\ 194021 Санкт-Петербург, Россия \\ e-mail: a.panchak@mail.ioffe.ru
}

Поступило в Редакцию 29 октября 2021 г.

В окончательной редакции 2 декабря 2021 г.

Принято к публикации 7 декабря 2021 г.

В фотоэлектрических преобразователях концентрированного солнечного излучения утонение подложки позволяет уменьшить тепловое сопротивление кристалла и снинзить рабочую температуру активной области. Однако при этом механические напряжения в нем увеличиваются. Настоящая работа поднимает вопрос баланса между механической прочностью образца и уменьшением его рабочей температуры за счет утонения подложки.

Ключевые слова: фотоэлектрические преобразователи, теплоотвод, температурный режим, механические напряжения.

DOI: $10.21883 / J T F .2022 .03 .52141 .283-21$

\section{Введение}

Полупроводниковые фотоэлектрические преобразователи (ФЭП) являются основными элементами систем преобразования солнечной энергии в электрическую. В космических солнечных батареях ФЭП работают c неконцентрированным излучением, тогда как в наземных модулях экономически эффективным является преобразование концентрированного солнечного излучения [1-3]. При работе в условиях интенсивного (при концентрации солнечного излучения 400-1000 крат) облучения значения КПД ФЭП могут достигать 47\% [4]. Однако предельные эффективности регистрируются при стандартных условиях тестирования $\left(25^{\circ} \mathrm{C}\right)$, тогда как в реальных системах всегда присутствует разогрев ФЭП. Поскольку эффективность преобразования излучения падает с ростом температуры, остро встает вопрос снижения (или стабилизации) температуры активной области ФЭП и отвода тепла в рабочем режиме при непрерывном облучении. Стандартная конструкция ФЭП подразумевает ввод излучения в активную область со стороны верхнего широкозонного слоя (окна). Под активной областью обычно располагается тонкий переходный слой и подложка, на которой проводился процесс эпитаксии структуры или на которую структура была перенесена при производстве ФЭП $[4,5]$. Конструктивное исполнение высокоэффективных многопереходных ФЭП предполагает использование пластин германия толщиной до $200 \mu \mathrm{m}$ в качестве подложек.

До 50\% приходящей солнечной энергии, поступающей на ФЭП, преобразуется в электричество и выводится во внешнюю цепь, тогда как оставшаяся часть представляет собой тепло, нагревающее полупроводниковый кристалл. Для стабилизации рабочей температуры концентраторные ФЭП монтируются на теплоотводящее основание [6]. В зависимости от выбранных материалов коэффициенты теплового расширения теплоотвода и полупроводникового кристалла могут значительно различаться. Так как процедура монтажа обычно предполагает нагрев чипа ФЭП до высоких температур $\left(\sim 200^{\circ} \mathrm{C}\right)$ и последующее охлаждение, толстая подложка должна обеспечить кристаллу дополнительную жесткость, препятствовать появлению критических напряжений и дефектов в активной области и предотвратить разрушение кристалла. В качестве эффективного способа снижения рабочей температуры активной области и образца в целом следует рассматривать уменьшение толщины подложки с соответствующим одновременным снижением общего теплового сопротивления, определяемое ее материалом и толщиной. Очевидно, максимальный эффект может быть достигнут при некоторой толщине подложки, которой оказывается достаточно для обеспечения механической прочности и работоспособности ФЭП с учетом температурных режимов его жизненного цикла. В настоящей работе обсуждается вопрос баланса между уменьшением рабочей температуры активной области (за счет утонения подложки) и сохранением достаточной механической прочности полупроводниковой структуры, смонтированной на теплоотводе.

\section{1. Перегрев активной области}

Моделирование тепловых режимов и определение температуры проводилось для ФЭП, GaAs активная область которого сформирована на германиевой подложке. Для этого использовался пакет COMSOL Multiphysics. 
ФЭП имел размеры $3 \times 3 \mathrm{~mm}$. Толщина подложки изменялась от 200 до $3 \mu \mathrm{m}$. В качестве материала для теплоотвода, на котором устанавливался ФЭП, рассматривались медь $(\mathrm{Cu})$, ковар (Kovar), сталь (Steel), алюмонитридная $(\mathrm{AlN})$ и алюмооксидная $\left(\mathrm{Al}_{2} \mathrm{O}_{3}\right)$ керамики. Размер теплоотвода составлял $10 \times 12 \times 1 \mathrm{~mm}^{3}$.

Распределение облученности, формируемое концентратором на ФЭП, предполагалось „гауссовым“ при кратностях концентрирования излучения $C=100-1000 \mathrm{X}$ с размером освещаемой области $2.8 \mathrm{~mm}$ в диаметре и равномерным при $C=1 \mathrm{X}$. Плотность потока солнечного облучения излучения, поступающего на концентратор, принималась равной $1000 \mathrm{~W} / \mathrm{m}^{2}$.

В ходе моделирования было установлено, что наличие припойного слоя $\mathrm{Sn}_{0.62} \mathrm{~Pb}_{0.36} \mathrm{Ag}_{0.02}$ толщиной до $10 \mu \mathrm{m}$ не оказывает существенного влияния на температуру и механические напряжения внутри полупроводникового кристалла (разница результатов моделирования с припоем и без него не превышала $2 \%$ ), поэтому в проводимых оценках вклад характеристик припоя в возникающие напряжения в полупроводниковом кристалле принимался пренебрежимо малым и не учитывался. Кроме того, пайка ФЭП непосредственно на материал теплоотвода затруднительна, поэтому теплоотводящие платы покрывают тонким слоем меди. Было установлено, что при толщине медной пленки менее $10 \mu \mathrm{m}$ существенного влияния на результаты моделирования также нет. Таким образом, сейчас и далее принято допущение: полупроводниковая структура жестко смонтирована непосредственно на теплоотвод, при этом между ними имеется идеальный термический контакт.

Поскольку тепловое сопротивление на границе ФЭП-теплоотвод значительно меньше, чем на границе ФЭП-воздух, и основной поток тепла в кристалле направлен от фотоприемной поверхности (активной области) в сторону тыльного контакта и теплоотвода, перегрев активной области может быть определен из уравнения теплопроводности [7]

$$
q=-\chi \nabla T
$$

где $q$ - поток тепла, $\chi$ - теплопроводность.

При „гауссовом“ (а также при равномерном) распределении облученности по фотоприемной поверхности максимальная температура наблюдается в центре ФЭП вблизи активной области. На рис. 1 приведен перегрев в этой точке относительно комнатной температуры $\left(25^{\circ} \mathrm{C}\right)$ в режиме холостого хода. Так, при кратности концентрирования солнечного излучения $1000 \mathrm{X}$ отчетливее всего видна разница влияния на рабочую температуру толщины подложки (рис. 1). Следует отметить, что в представленном варианте медный теплоотвод имеет максимальный (для рассматриваемых материалов) коэффициент теплопроводности и одновременно наибольшую разность коэффициентов линейного расширения (см. таблицу). Примеры использования теплоотводов (в том числе из меди) в концентраторных фотоэлектрических модулях приведены в $[1,2,8,9]$.
Эффективность передачи тепла от активной области через подложку к теплоотводу будет зависеть от характеристик последнего. Так, с уменьшением толщины германиевой подложки не каждый теплоотвод сможет обеспечивать условия для понижения температуры активной области ФЭП (рис. 2). Для материалов с теплопроводностью меньше германия (Kovar и $\mathrm{Al}_{2} \mathrm{O}_{3}$, см. таблицу) утонение полупроводниковой подложки приводит к повышению температуры $p-n$-перехода. Теплопроводность стали близка к теплопроводности германия, поэтому с уменьшением толщины подложки температура $p-n$ перехода будет меняться незначительно.

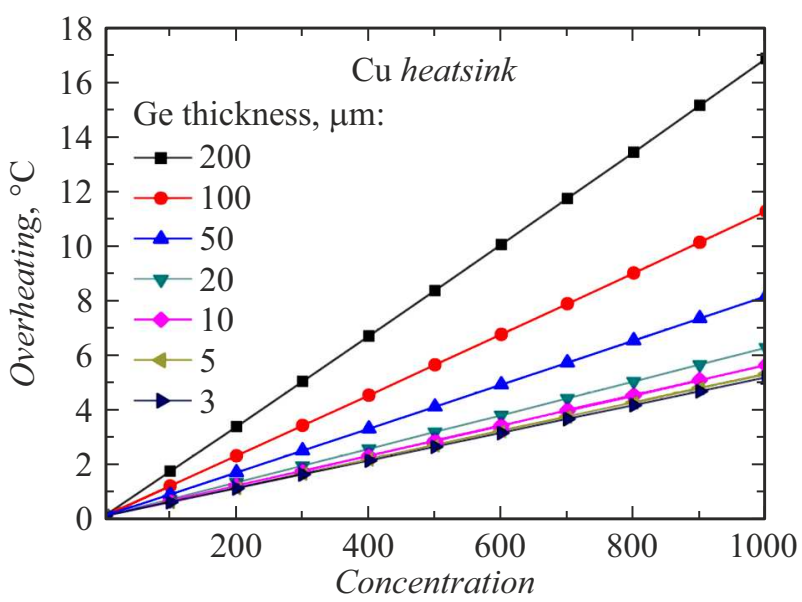

Рис. 1. Перегрев активной области ФЭП в центре относительно окружающей среды в зависимости от кратности концентрирования солнечного излучения и изменения толщины $\mathrm{Ge}-$ подложки при использовании медного теплоотвода толщиной $1 \mathrm{~mm}$. Режим работы ФЭП - холостой ход. Температура тыльной стороны теплоотвода поддерживалась на уровне окружающей среды $\left(25^{\circ} \mathrm{C}\right)$.

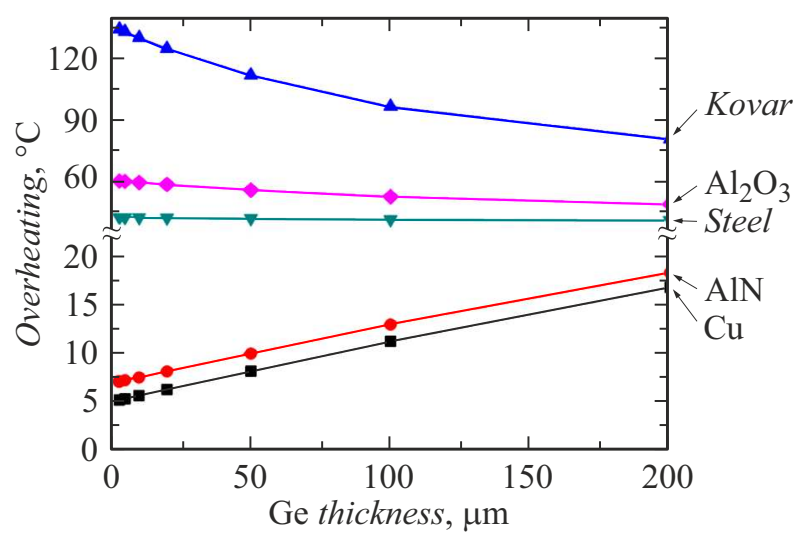

Рис. 2. Перегрев активной области ФЭП в центре относительно окружающей среды в зависимости от толщины Geподложки при использовании теплоотводов из меди $(\mathrm{Cu})$, алюмонитрида (AlN), стали, алюмооксида $\left(\mathrm{Al}_{2} \mathrm{O}_{3}\right)$ ковара (Kovar). Режим работы ФЭП - холостой ход. Температура тыльной стороны теплоотвода поддерживалась на уровне окружающей среды $\left(25^{\circ} \mathrm{C}\right)$. Кратность концентрирования $C=1000 \mathrm{X}$. 
Значения теплопроводности и коэффициента линейного теплового расширения германия (Ge), арсенида галлия (GaAs), меди $(\mathrm{Cu})$, алюмонитридной керамики $(\mathrm{AlN})$, ковара (Kovar), стали (Steel), алюмооксидной керамики $\left(\mathrm{Al}_{2} \mathrm{O}_{3}\right)$ при комнатной температуре [10-23]

\begin{tabular}{l|c|c|c|c|c|c|c}
\hline Материал & $\mathrm{Ge}$ & $\mathrm{GaAs}$ & $\mathrm{Cu}$ & $\mathrm{AlN}$ & Kovar & Steel & $\mathrm{Al}_{2} \mathrm{O}_{3}$ \\
\hline Теплопроводность $(\chi), \mathrm{W} /(\mathrm{m} \cdot \mathrm{K})$ & 61 & 33 & 401 & 287 & 14 & 47 & 35 \\
\hline Коэффициент температурного расширения $\times 10^{-6}, \mathrm{~K}^{-1}$ & 6.1 & 6 & 16.5 & 5.3 & 6.2 & 13.8 & 5.6
\end{tabular}

Применение теплоотводов на основе материалов с коэффициентом теплопроводности, превышающим аналогичный показатель полупроводниковой германиевой подложки, обеспечивает снижение рабочей температуры ФЭП по мере ее утонения. Так, например, при кратности концентрирования солнечного излучения $C=1000 \mathrm{X}$ температура в центре активной области ФЭП, смонтированного на стабилизируемом при $T=25^{\circ} \mathrm{C}$ теплоотводе из алюмонитридной керамики, будет составлять $43^{\circ} \mathrm{C}$ (для режима холостого хода) при толщине $\mathrm{Ge}$ подложки $200 \mu \mathrm{m}$. Температура аналогичного образца с толщиной подложки $3 \mu \mathrm{m}$ в этих же условиях будет уже $32^{\circ} \mathrm{C}$. Таким образом, температура активной области утоненного ФЭП может быть снижена на $11^{\circ} \mathrm{C}$, что соответствует приросту КПД на 1\%.

\section{2. Механические напряжения в корпусированных ФЭП}

В процессе корпусирования ФЭП фиксируется на теплоотводе методом пайки составом $\mathrm{Sn}_{0.62} \mathrm{~Pb}_{0.36} \mathrm{Ag}_{0.02}$ (температура затвердевания припоя составляет $\left.\sim 160^{\circ} \mathrm{C}\right)$. Затем пара „ФЭП-теплоотвод“ остывает до комнатной температуры. В результате реализации такой технологической операции в полупроводниковой структуре ФЭП могут возникать механические напряжения из-за различия коэффициентов линейного расширения (сжатия) материала подложки и теплоотвода. Поэтому для предотвращения повреждений слоев активной области ФЭП из-за механических напряжений, инициируемых со стороны области контакта ФЭП и теплоотвода, толщина подложки должна оставаться значительной, что, как уже обсуждалось выше, будет препятствовать отводу избыточного тепла от $p-n$ перехода и приводить к общему перегреву ФЭП.

Несмотря на то что латеральные размеры (по осям $X$ и $Y$ ) моделируемого объекта значительно превышали вертикальный размер (по оси $Z$ ), деформации во всех направлениях по предварительной оценке были незначительны. Поэтому при расчетах было принято допущение о том, что рассматриваемый объект подвергается малой деформации. В этом случае можно использовать модель деформации объемного упругого твердого тела [24]. Результаты расчетов приведены в виде механических напряжений по Мизесу [25]. Такое представление позволяет напрямую сравнивать их с пределом текучести ис- следованных материалов. Моделирование проводилось в математическом пакете COMSOL Multiphysics с опорой на расчеты, приведенные в [26,27].

Были проведены расчеты напряжений, возникающих в структурах ФЭП $(3 \times 3 \mathrm{~mm})$ с германиевой подложкой при использовании различных теплоотводов (медь, ковар, сталь, керамики $\mathrm{Al}_{2} \mathrm{O}_{3}$ и $\left.\mathrm{AlN}\right)$. Температура окружающей среды принималась равной $25^{\circ} \mathrm{C}$. Таким образом, разница температур при выполнении технологической процедуры пайки ФЭП на теплоотвод и „холодным“ состоянием составляла $135^{\circ} \mathrm{C}$. В настоящей работе рассматривались модели с минимальным шагом дискретизации $1 \mu \mathrm{m}$ по оси $Z$ и $10 \mu \mathrm{m}$ по осям $X$ и $Y$, что оказывалось достаточным для построения наглядной картины механических напряжений.

Рис. 3 иллюстрирует типичное распределение напряжений в исследуемом ФЭП, зафиксированном на медном теплоотводе. Результаты приведены для вертикального сечения, проходящего через центр ФЭП и середину его боковой грани (точки $[0,0]$ и $[0,1.5])$. Напряжение в полупроводниковой структуре наблюдается вдоль всего контакта с теплоотводом, а вблизи края ФЭП возникают области с повышенным напряжением. Для всех материалов теплоотводов расчетные напряжения в подложке не превышали предела текучести германия [28]. При утонении Ge-подложки активная область становится ближе к контакту ФЭП-теплоотвод. В этом случае при значительном рассогласовании коэффициентов термического расширения полупроводниковой структуры и

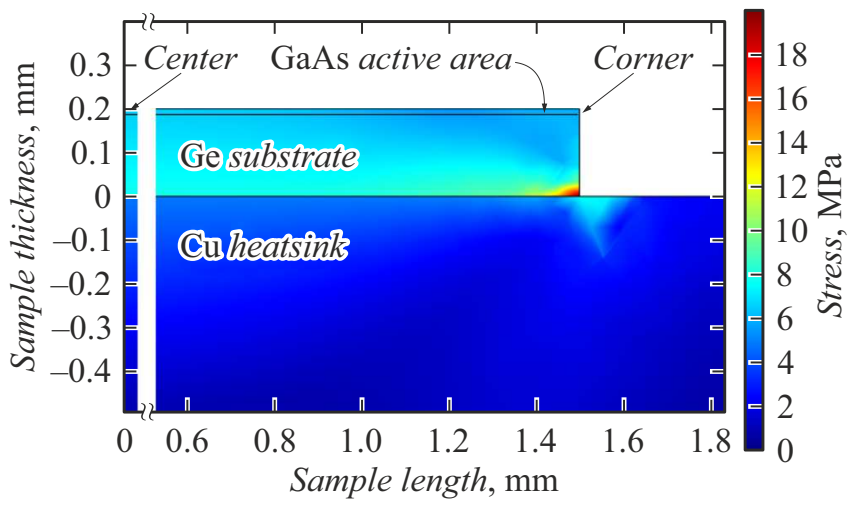

Рис. 3. Типичное распределение напряжений внутри образца с $200 \mu \mathrm{m}$ Ge-подложкой, смонтированного на медном теплоотводе. Данные приведены для вертикального сечения, проходящего через центр образца и центр боковой грани. 


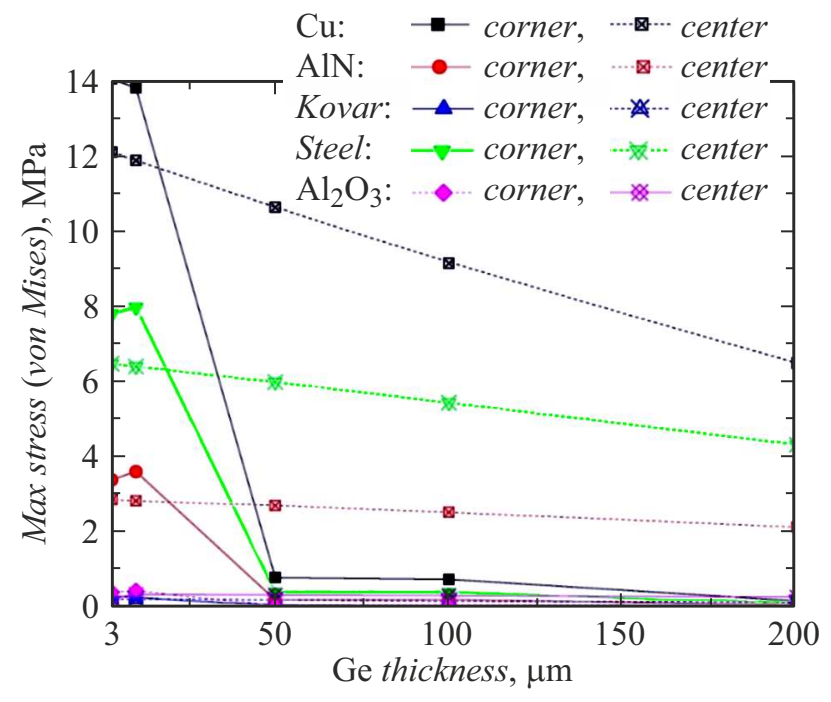

Рис. 4. Зависимость напряжения (по Мизесу) на границе активной области и подложки на углу кристалла (сплошные линии) и в центре кристалла (прерывистые линии) от толщины подложки при использовании теплоотводов из материалов: медь $(\mathrm{Cu})$, ковар (Kovar), сталь (Steel), алюмонитридная (AlN) и алюмооксидная $\left(\mathrm{Al}_{2} \mathrm{O}_{3}\right)$ керамики.

теплоотвода (медь, сталь, $\mathrm{Al}_{2} \mathrm{O}_{3}$ керамика (см. таблицу)) повышенные механические напряжения могут распространяться и на материал активной области (слой $\mathrm{GaAs}$ ).

На рис. 4 показана зависимость напряжения на границе подложка-активная область от толщины германиевой подложки для материалов теплоотвода: медь, ковар, сталь, керамики $\mathrm{Al}_{2} \mathrm{O}_{3}$ и AlN. Приведены значения напряжения на углу ФЭП и в его центре (точки отмечены на рис. 3 как „соrner“ и „сеnter"). Общая тенденция в распределении напряжений такова, что области с повышенными значениями расположены вблизи углов кристалла рядом с границей подложка-теплоотвод. По мере удаления от теплоотвода напряжения на углах релаксируют быстрее, чем в центре структуры. Так, при малой толщине подложки (до $10 \mu \mathrm{m}$ ) область повышенного напряжения на углах полупроводниковой структуры достигает активной области для всех вариантов теплоотвода. Особенно ярко этот эффект проявляется для медного, стального и керамического AlN теплоотводов, поскольку коэффициенты термического расширения этих материалов значительно отличаются от германиевого (см. таблицу). При толщине подложки более $50 \mu \mathrm{m}$ напряжения на углах резко снижались. В центре напряжение от толщины подложки убывало линейно. Так, при толщине подложки более $50 \mu \mathrm{m}$ оно оказывалось больше, чем на углу.

В образцах с теплоотводами из материалов с коэффициентом линейного расширения, близким к германию, наблюдаются самые низкие значения напряжения в активной области: $0.3 \mathrm{MPa}$ у ковара и $0.4 \mathrm{MPa}$ у $\mathrm{Al}_{2} \mathrm{O}_{3}$. Однако теплопроводность у них ниже, чем у герма- ния, поэтому использование их в качестве теплоотвода возможно только для образцов с толстой подложкой в специальных условиях.

Для ФЭП на медном теплоотводе наблюдаются самые значительные структурные напряжения, достигающие активной области. В этом случае использование ФЭП с толщиной подложки менее $100 \mu \mathrm{m}$ недопустимо, так как возникающие напряжения выше предела текучести материала активной области GaAs (10 MPa [29]). Следует также учитывать, что в процессе корпусирования на ФЭП со стороны активной области могут оказываться дополнительные механические воздействия, например при контактировании измерительным зондом или при установке (разварке) верхней токоотводящей шины. Для устойчивости ФЭП к таким воздействиям необходимо обеспечить „запас прочности“, оптимизируя толщину германиевой подложки.

При использовании близкого по теплопроводности к меди керамического AlN-теплоотвода максимальное напряжение в районе активной области составляет $3.6 \mathrm{MPa}$ в углу кристалла и $2.9 \mathrm{MPa} \mathrm{в} \mathrm{центре.} \mathrm{Максимальная} \mathrm{раз-}$ ница напряжений в структурах с тонкой и стандартной подложкой не превышает $1.5 \mathrm{MPa}$, что позволяет обеспечить утоненным ФЭП благоприятный температурный режим без снижения фотоэлектрических характеристик из-за механических напряжений.

\section{Заключение}

В работе рассмотрены варианты уменьшения рабочей температуры GaAs $p-n$-перехода в ФЭП с утоняемой германиевой подложкой при работе в условиях преобразования сконцентрированного солнечного излучения. Применяемая процедура корпусирования (пайки) приводит к возникновению механических напряжений, инициируемых со стороны области контакта ФЭП и теплоотвода, поэтому процесс утонения одновременно с уменьшением рабочей температуры приводит к увеличению структурных напряжений в ФЭП. Такие напряжения могут распространяться по полупроводниковому материалу, нарастать и достигать активной области ФЭП, снижая его КПД. В свою очередь, использование теплоотводов на основе материалов с теплопроводностью, большей, чем у германия, всегда снижает рабочую температуру ФЭП с утоненной подложкой.

Показано, что при использовании медного теплоотвода в условиях освещенности $C=1000 \mathrm{X}$ расчетная температура GaAs активной области уменьшается с 41 до $30^{\circ} \mathrm{C}$ при утонении Ge подложки с 200 до $3 \mu \mathrm{m}$, однако вместе с тем в активной области возникают механические напряжения, превышающие предел текучести ее материала, что может стать причиной разрушения образцов толщиной менее $100 \mu \mathrm{m}$.

Наиболее перспективным материалом теплоотвода с точки зрения уменьшения рабочей температуры активной области и возникающих в ней механических 
напряжений является $\mathrm{AlN}-$ керамика. При уменьшении толщины подложки с 200 до $3 \mu \mathrm{m}$ максимальные напряжения в напаянном ФЭП увеличиваются с 2 до $3.6 \mathrm{MPa}$, что значительно меньше предела текучести материала активной области - GaAs (10 MPa). Вместе с этим ожидается уменьшение температуры активной области с 43 до $32^{\circ} \mathrm{C}$ в режиме холостого хода или с 36 до $28^{\circ} \mathrm{C}$ в режиме оптимальной нагрузки при кратности концентрирования $C=1000 \mathrm{X}$, что эквивалентно увеличению КПД приблизительно на $1 \%$ [30,31].

\section{Финансирование работы}

Работы проведены при финансовой поддержке Министерства науки и высшего образования РФ, Соглашение № 075-15-2021-989 от 23.09.2021 г. (Уникальный идентификатор контракта RF----225121X0054).

\section{Конфликт интересов}

Авторы заявляют, что у них нет конфликта интересов.

\section{Список литературы}

[1] А.В. Чекалин, А.В. Андреева, Н.Ю. Давидюк, Н.С. Потапович, Н.А. Садчиков, В.М. Андреев, Д.А. Малевский. ЖТФ, 91 (6), 915 (2021). DOI: 10.21883 JTF.2021.06.50859.314-20

[2] M. Steiner, A. Bösch, A. Dilger, F. Dimroth, T. Dörsam, M. Muller, T. Hornung, G. Siefer, M. Wiesenfarth, A.W. Bett. Prog. Photovolt: Res. Appl., 23 (10),1323 (2014). DOI: $10.1002 /$ pip.2568

[3] N.A. Pakhanov, V.M. Andreev, M.Z. Shvarts, O.P. Pchelyakov. Optoelectronics, Instrumentation and Data Processing, 54, 187 (2018). DOI: 10.3103 S8756699018020115

[4] J.F. Geisz, R.M. France, K.L. Schulte, M.A. Steiner, A.G. Norman, H.L. Guthrey, M.R. Young, T. Song, T. Moriarty. Nature Energy, 5, 326 (2020). DOI: 10.1038 s41560-020-0598-5

[5] X. Zhang, J. Hu, Y. Wu, F. Lu. J. Phys. D: Appl. Phys., 42, 145401 (2009). DOI: 10.1088/0022-3727/42/14/145401

[6] Н.Ю. Давидюк, А.В. Андреева, Д.А. Малевский, П.В. Покровский, Н.А. Садчиков, А.В. Чекалин, В.М. Андреев. Письма в ЖТФ, 46 (9), 29 (2020).

DOI: 10.21883 PJTF.2020.09.49369.18239

[N.Yu. Daviduk, A.V. Andreeva, D.A. Malevsky, P.V. Pokrovsky, N.A. Sadchikov, A.V. Chekalin, V.M. Andreev. Tech. Phys. Lett., 46, 436 (2020). DOI: 10.1134/S1063785020050041]

[7] L.D. Landau, E.M. Lifshitz. Theory of Elasticity (3rd ed.) (Elsevier, 1986), v. 7, Ch. V, p. 152. DOI: $10.1063 / 1.3057037$

[8] А.В. Андреева, Н.Ю. Давидюк, Д.А. Малевский, А.Н. Паньчак, Н.А. Садчиков, А.В. Чекалин. ФТП, 52, 3 (2018). DOI: 10.21883 JTF.2021.02.50365.155-20

[9] G. Peharz, J.P.F. Rodríguez, G. Siefer, A.W. Bett. Prog. Photovolt: Res. Appl., 19, 54 (2011). DOI: 10.1002 pip.987

[10] A.S. Okhotin, A.S. Pushkarskii, V.V. Gorbachev. Thermophysical Properties of Semiconductors (Atom, Publ. House, M., 1972)

[11] J.S. Blakemore. J. Appl. Phys., 53 (10), 123 (1982). DOI: $10.1063 / 1.331665$
[12] M. White, J. Gran, N. Tomlin, J. Lehman. Metrologia, 51, S245 (2014). DOI: 10.1088/0026-1394/51/6/S245

[13] G.A. Slack, R.A. Tanzilli, R.O. Pohl, J.W. Vandersande. J. Phys. Chem. Sol., 48 (7), 641 (1987). DOI: 10.1016/0022-3697(87)90153-3

[14] M. Bukhari, M.S.J. Hashmi, D. Brabazon. In The 2nd International Malaysia-Ireland Joint Symposium on Engineering, Science and Business (IMiEJS), 2012 At: Putra World Trade Centre, Kuala Lumpur, Malaysia.

[15] E. Ranjbarnodeh, S. Serajzadeh, A.H. Kokabi, A. Fischer. J. Mater. Sci., 46, 3225 (2011). DOI: $10.1007 / \mathrm{s} 10853-010-5207-8$

[16] W. Martienssen, H. Warlimont Springer handbook of Condensed Matter and Materials Data (Springer, Berlin, 2005), p. 431. DOI: $10.1007 / 3-540-30437-1$

[17] S.I. Novikova. Sov. Phys. Sol. State, 2 (1),37 (1960).

[18] S.I. Novikova. Sov. Phys. Sol. State, 3 (1),129 (1961).

[19] D. Minakov, P. Levashov. Phys. Rev. B., 92, 224102 (2015). DOI:10.1103/PhysRevB.92.224102

[20] G.A. Slack, S.F. Bartram. J. Appl. Phys., 46 (1), 89 (1975). DOI: $10.1063 / 1.321373$

[21] L. Del Castillo, D. Schatzel, C. Weber, T. Hatake, M. Mojarradi, E.A. Kolawa. In Proc. 4th Int. Planetary Probe Workshop, (2006).

[22] G. Sun, Z. Chen, Z. Liu. J. Mater. in Civil Engineer., 23, 1017, (2011). DOI: 10.1061/(ASCE)MT.1943-5533.0000271

[23] Y. Wang, J.J. Wang, W.Y. Wang, Z. Mei, S. Shang, L. Chen, Z. Liu. J. Physics-Condensed Matter, 22, 202201 (2010). DOI: $10.1088 / 0953-8984 / 22 / 20 / 202201$

[24] L.D. Landau, E.M. Lifshitz. Theory of Elasticity (3rd ed.) (Elsevier, 1986), v. 7, Ch. I, p. 2. DOI: $10.1063 / 1.3057037$

[25] R.M. Jones. Deformation Theory of Plasticity (Bull Ridge Corporation, 2009), Section 4.5.6, p. 151. ISBN: 978-0-9787223-1-9

[26] Y. Deng, S. Tang, D. Tung. 2018 IEEE International Conference on Applied System Invention (ICASI), (Chiba, Japan, 2018), p. 1149-1151. DOI: $10.1109 /$ ICASI.2018.8394487

[27] M. Vajdi, F. Moghanlou, F. Sharifian Jazi, M. Shahedi Asl, M. Shokouhimehr. J. Composites and Compounds, 2 (2), 35 (2020). DOI: $10.29252 /$ jcc.2.1.5

[28] Yu.V. Milman, I.V. Gridneva, A.A. Golubenk. Sci. Sinter., 39, 67 (2007). DOI: 10.2298/SOS0701067M

[29] I. Yonenaga, K. Sumino. J. Appl. Phys., 71, 4249 (1992). DOI: $10.1063 / 1.350805$

[30] C. Algora, I. Rey-Stolle. Handbook of Concentrator Photovoltaic Technology (Willey, United Kingdom, 2016), p. 264. DOI: $10.1002 / 9781118755655$

[31] E.F. Fernández, G. Siefer, M. Schachtner, A.J. García Loureiro, P. Pérez-Higueras. AIP Conf. Proceed., 1477, 189 (2012). DOI:10.1063/1.4753865 